Revista

A Cor
das Letras

\title{
Presença abençoada ou ausência sentida: a água na toponímia da Bahia
}

\author{
A blessed presence or an absence felt: the water in Babia toponymy
}

\author{
Clese Mary Prudente* \\ Universidade do Estado da Babia \\ Salvador, Bahia, Brasil \\ Celina Márcia Abbade** \\ Universidade do Estado da Babia \\ Salvador, Bahia, Brasil
}

\begin{abstract}
Resumo: A Onomástica, ramo da Lexicologia que estuda os nomes próprios de pessoas (antropônimos) e de lugares (topônimos), representa uma fonte de estudo da língua e sua relação com o patrimônio cultural de um povo. Nessa perspectiva, considerando os topônimos como testemunhos da história da língua e buscando conciliar as abordagens teóricas da Etnolinguística e da Lexicologia, com foco nos estudos onomásticos, discute-se, neste artigo, a importância da água, como presença abençoada ou ausência sentida, no processo de nomeação do espaço na Bahia. Povoados, vilas, aldeias surgiram às margens de rios, lagoas e riachos e o povo aprendeu a identificar o lugar por essa presença, imprescindível à existência de vida. Analisa-se, nesse contexto, o número significativo de hidrotopônimos, uma taxe de natureza física, no corpus estudado, que envolve os 169 designativos dos municípios presentes nos volumes XX e XXI da Enciclopédia dos Municípios Brasileiros, publicados pelo Instituto Brasileiro de Geografia e Estatística (IBGE) em 2 de julho de 1958. De acordo com o sistema classificatório proposto por Dick $(1990,1992)$ para a realidade toponímica brasileira, as taxes de natureza física refletem a visão imediata da terra, causa nominativa principal na toponímia baiana analisada, resultado que se contrapõe ao registrado em outras regiões do Brasil, onde a supremacia da colonização portuguesa, predominantemente marcada pela fé religiosa, se sobrepõe à força da natureza no ato de nomear o lugar.
\end{abstract}

Palavras-chave: Onomástica. Toponímia. Hidrotopônimos. Municípios baianos.

\begin{abstract}
Onomastics, a branch of Lexicology that studies personal names (anthroponyms) and place names (toponyms), represents a source of language study in relation to the cultural heritage of a people. In this perspective, considering toponyms as testimonies of the language history and seeking to conciliate the theoretical approaches of Ethnolinguistics and Lexicology, focusing on onomastic studies, this article discusses the importance of water, as a blessed presence or an absence felt, in the process of naming space in Bahia. Towns and villages were set on the banks of rivers, lagoons and streams, and people have learned to identify the place by that presence, essential to life existence. In this context, it is analyzed the significant number of hydrotoponyms, a tax of physical nature, in the corpus studied, which involves the names of Bahia municipalities present in volumes XX and XXI of the Enciclopédia dos Municípios Brasileiros, published by Instituto Brasileiro de Geografia e Estatística (IBGE) on July 2, 1958. According to the classification system proposed by Dick $(1990,1992)$ for Brazilian toponymic reality, taxes of physical nature reflect the immediate view of the land, the main nominative cause in the analyzed toponymy. This result contrasts with that recorded in other regions of Brazil, where the supremacy of Portuguese colonization, predominantly marked by religious faith, overlaps with the force of nature in the act of naming the place.
\end{abstract}

Keywords: Onomastics. Toponymy. Hydrotoponyms. Bahia municipalities.

**Mestre em Estudos de Linguagem (UNEB). E-mail: cleseprudente@gmail.com.

* Doutora de Letras e Linguística (UFBA), professora da Universidade do Estado da Bahia. Email: celinabbade@gmail.com 


\section{CONSIDERAÇÕES INICIAIS}

A água é, sem dúvida, um bem natural insubstituível e essencial à manutenção da vida. A sua presença abençoada tornou possível o acesso e a sobrevivência dos primeiros desbravadores das terras baianas. Utilizadas como caminhos, as vias fluviais guiavam os colonizadores e asseguravam a fixação de núcleos populacionais às suas margens, enquanto a sua ausência sentida na região do semiárido ensinou o sertanejo a conviver com os longos períodos de estiagem. E esse elemento tão fundamental influenciou de maneira significativa o ato de nomeação do espaço.

$\mathrm{O}$ ato de dar nomes insere-se no campo de estudo da Onomástica, área da Lexicologia que se dedica às lexias que individualizam seres (Antroponímia) e lugares (Toponímia). Constituídos de elementos linguísticos capazes de preservar fatos culturais de uma área geográfica, os signos onomásticos representam uma fonte de estudo da língua e sua relação com o patrimônio cultural de um povo. Como afirma Dick (2007),

A Onomástica é muito mais do que um mero fator auxiliar do agir e do viver individual ou coletivo; é indício de rumos tomados pelos falares ao longo dos períodos históricos, de comportamentos presentes no cotidiano e de atitudes morais ou operosas valorizadas pela população (DICK, 2007, p. 144).

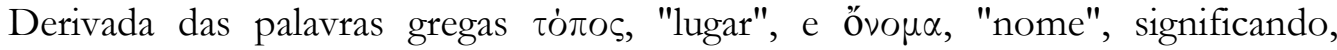
portanto, "nome de lugar", a Toponímia tem como objeto de estudo o topônimo e se constitui na parte da Onomástica voltada para a análise de aspectos etimológicos, morfológicos, semânticos e motivacionais dos nomes de lugares, ou designativos geográficos, de acidentes físicos (rios, riachos, morros, baias, ilhas etc.) e humanos (cidades, aldeias, vilas, povoados etc.).

Nesse sentido, compreendendo os topônimos como testemunhos da história da língua, tendo em vista que eles registram os contatos linguísticos e culturais e guardam marcas de um passado histórico, entende-se que os estudos toponímicos se relacionam à Etnolinguística, área dos estudos linguísticos que se preocupa em perceber a influência da cultura no léxico e na gramática de uma língua, de acordo com as atividades, a estrutura social e o ambiente geográfico do povo que a usa (ISQUERDO, 2008, p. 44).

Assim, conciliando as abordagens teóricas da Etnolinguística e da Lexicologia, com foco na Onomástica, apresenta-se parte do resultado da pesquisa empreendida com topônimos dos municípios do estado da Bahia, documentados nos volumes XX e XXI da Enciclopédia dos Municípios Brasileiros (doravante EMB), publicados pelo IBGE em 2 de julho de 1958. Neste trabalho, analisa-se o número significativo de hidrotopônimos no corpus estudado, comprovando a importância da água no processo de nomeação do espaço na Bahia.

Esse estudo faz parte da pesquisa Babia de Todos os Cantos e Recantos: marcas identitárias e culturais na Toponímia da Babia, desenvolvida e concluída no Programa de Pós-Graduação em Estudos de Língua e Linguagens (PPGEL) da Universidade do Estado da Bahia 
(UNEB), e insere-se no macro projeto ATOBAH - Atlas Toponímico da Bahia, em desenvolvimento no NEL - Núcleo de Estudos Lexicais, coordenado pela Profa. Dra. Celina Márcia de Souza Abbade.

\section{OS CAMINHOS DAS ÁGUAS NOS TERRITORIOS DE IDENTIDADE DA BAHIA}

Localizado na região Nordeste do Brasil e ocupando uma área de $567.295 \mathrm{~km}^{2}$, o estado da Bahia, quinto do país em extensão territorial (BAHIA, 2001), está politicamente dividido em municípios, contando atualmente com 417.

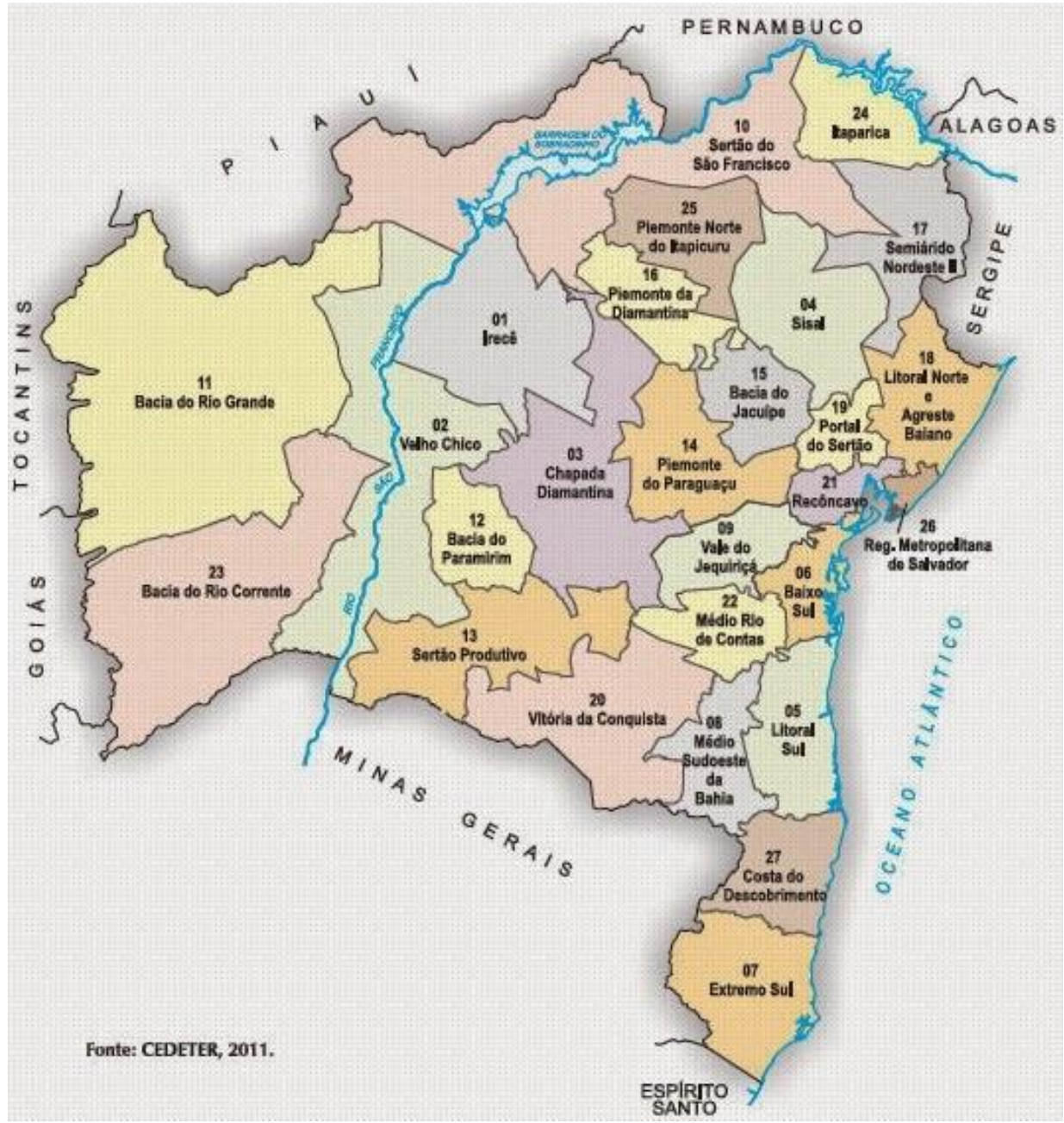

Figura 1 - Mapa dos Territórios de Identidade do Estado da Bahia. Fonte: CEDETER, 2011. 
Adotando a dimensão territorial desenvolvida pela Secretaria de Desenvolvimento Territorial (SDT) do Ministério do Desenvolvimento Agrário (MDA), o Governo da Bahia, através do Decreto 12.354, de 26.08.2010, agrupou os municípios em 27 Territórios de Identidade (TI) (BAHIA, 2012), (Figura 1) levando em consideração fatores próximos às realidades territoriais:

- Ambiente: atributos relativos aos recursos naturais, áreas de proteção, patrimônio natural e problemas ambientais;

- Colonização: processo de ocupação territorial;

- Economia: processos produtivos, polos de desenvolvimento, geração de emprego e da estrutura econômica local;

- Etnia: interferência dos grupos que agem baseados em suas crenças e perfis étnicos;

- Dimensão sociocultural: história, valores, visões compartilhadas, significados, códigos, ícones, tradições e culturas populares.

Como recurso natural, a água foi considerada como um fator preponderante na identificação e delimitação desses territórios, o que pode ser comprovado no ato de nomeação: dos vinte e sete TI, dez são nomeados a partir dos rios que os percorrem e que possibilitaram o processo de colonização e ocupação territorial, permitindo que se associe a presença da água à causa nominativa desses territórios: TI 02 - Velho Chico; TI 09 - Vale do Jiquiriçá; TI 10 - Sertão do São Francisco; TI 11 - Bacia do Rio Grande; TI 12 - Bacia do Paramirim; TI 14 - Piemonte do Paraguaçu; TI 15 - Bacia do Jacuípe; TI 22 - Médio Rio de Contas; TI 23 - Bacia do Rio Corrente; TI 25 - Piemonte Norte do Itapicuru.

Entende-se por Bacia Hidrográfica um conjunto de terras drenadas por um rio principal, seus afluentes e subafluentes. Considerando as áreas de drenagem dos principais cursos d'água e seus afluentes, o Estado da Bahia pode ser dividido em 13 bacias hidrográficas, a saber: São Francisco, Vaza-Barris, Real, Itapicuru, Inhambupe, Recôncavo Norte, Paraguaçu, Recôncavo Sul, Contas, Leste, Pardo, Jequitinhonha e Extremo Sul. Dessas a mais importante é, sem dúvida, a bacia do Rio São Francisco, que envolve sub-bacias, dentre as quais se destacam as bacias dos rios Carinhanha, Corrente, Grande, Carnaíba de Dentro, Santo Onofre, Paramirim, Jacaré, Verde e Salitre (BAHIA, 2003).

Tanto os temporários, que cortam o território central e norte do Estado (na região semiárida), quanto os de regime permanente, localizados nas regiões úmidas do oeste, litoral e extremo sul, os rios representaram um fator primordial no processo de povoamento e ocupação do solo e na vida do povo ribeirinho. Povoados, vilas e aldeias surgiram às margens de rios, lagoas, poços e riachos e o povo aprendeu a identificar o lugar por essa presença, imprescindível à existência de vida. 


\section{PRESENÇA ABENÇOADA OU AUSÊNCIA SENTIDA: A HIDROTOPONIMIA DOS MUNICIPIOS BAIANOS}

Na pesquisa inicial, começou-se pela organização do corpus em Territórios de Identidade. Em sequência, os 169 topônimos foram classificados de acordo com o modelo teórico-metodológico proposto por Dick (1990; 1992) para um trabalho toponímico, o qual prevê vinte e sete taxes para a realidade toponímica brasileira, considerando duas ordens de consequência:

I. De natureza antropocultural, relacionadas a aspectos sociais, históricos e culturais:

a) Animotopônimos: relativos à vida psíquica, à cultura espiritual;

b) Antropotopônimos: relativos aos nomes próprios individuais;

c) Axiotopônimos: relativos aos títulos e dignidades que acompanham nomes próprios individuais; continentes;

d) Corotopônimos: relativos a nomes de cidades, países, estados, regiões e

e) Cronotopônimos: relativos aos indicadores cronológicos representados pelos adjetivos novo(a), velho(a);

f) Dirrematopônimos: constituídos de frases ou enunciados linguísticos;

g) Ecotopônimos: relativos às habitações em geral;

h) Ergotopônimos: relativos aos elementos da cultura material;

i) Etnotopônimos: relativos aos elementos étnicos isolados ou não (povos, tribos, castas);

j) Hierotopônimos: relativos a nomes sagrados de crenças diversas, a efemérides religiosas, às associações religiosas e aos locais de culto. Podem ser subdivididos em hagiotopônimos: nomes de santos, ou santas, do hagiológio católico romano; e mitotopônimos: relativos a entidades mitológicas;

k) Numerotopônimos: relativos aos adjetivos numerais;

l) Historiotopônimos: relativos aos movimentos de cunho histórico, a seus membros e às datas comemorativas;

m) Hodotopônimos: relativos às vias de comunicação urbana ou rural;

n) Poliotopônimos: constituídos pelos vocábulos vila, aldeia, cidade, povoação, arraial;

o) Sociotopônimos: relativos às atividades profissionais, aos locais de trabalho $\mathrm{e}$ aos pontos de encontro da comunidade;

p) Somatotopônimos: empregados em relação metafórica à parte do corpo humano ou do animal.

II. De natureza física, relacionadas ao ambiente físico:

a) Astrotopônimos: relativos aos corpos celestes em geral;

b) Cardinotopônimos: relativos às posições geográficas em geral;

c) Cromotopônimos: relativos à escala cromática;

d) Dimensiotopônimos: relativos às dimensões dos acidentes geográficos; 
e) Fitotopônimos: relativos aos vegetais;

f) Geomorfotopônimos: relativos às formas topográficas;

g) Hidrotopônimos: relativos a acidentes hidrográficos em geral;

h) Litotopônimos: relativos aos minerais e à constituição do solo;

i) Meteorotopônimos: relativos a fenômenos atmosféricos;

j) Morfotopônimos: relativos às formas geométricas;

k) Zootopônimos: relativos aos animais.

A predominância de taxes de natureza física no corpus analisado reflete a importância dos elementos da natureza (a flora, a fauna, a geomorfologia, a hidrografia, os recursos minerais) para aqueles que formaram o povo da Bahia, um estado que envolve três dos seis biomas do Brasil: Mata Atlântica, Cerrado e Caatinga, cada um com sua diversidade biológica. Tal riqueza se sobrepõe à força da colonização portuguesa, marcada pela fé religiosa e a forte influência do Catolicismo.

Conforme Dick e Seabra (2002), assim como a religião e a fé, as águas e os rios formaram, desde o inicio da ocupação da terra, os paradigmas de uma ampla rede onomástica. Enchendo os olhos tanto dos colonizadores quanto dos seus primeiros habitantes, o líquido precioso se faz presente nas diversas camadas do tapete onomástico que recobre o solo baiano. No Quadro 1, pode-se verificar os hidrotopônimos, designativos relacionados à água, presentes no corpus analisado, distribuídos em cada Território de Identidade.

\begin{tabular}{|l|l|}
\hline \multicolumn{1}{|c|}{ Territórios de Identidade } & \multicolumn{1}{c|}{ Hidrotopônimos $^{\mathbf{1}}$} \\
\hline 01 - Irecê & Irecê \\
\hline $02-$ Velho Chico & $\begin{array}{l}\text { Barra } \\
\text { Paratinga } \\
\text { Riacho de Santana }\end{array}$ \\
\hline 03 - Chapada Diamantina & $\begin{array}{l}\text { Barra da Estiva } \\
\text { Rio de Contas } \\
\text { Utinga }\end{array}$ \\
\hline 06 - Baixo Sul & $\begin{array}{l}\text { Camamu } \\
\text { Ituberá }\end{array}$ \\
\hline 08 - Médio Sudoeste da Bahia & Iguaí \\
\hline $10-$ Sertão do São Francisco & Remanso \\
\hline 12 - Bacia do Paramirim & Paramirim \\
\hline $13-$ Sertão Produtivo & Ituaçu \\
\hline $15-$ Bacia do Jacuipe & $\begin{array}{l}\text { Ipirá } \\
\text { Riachão do Jacuípe }\end{array}$ \\
\hline
\end{tabular}

\footnotetext{
${ }^{1}$ Para classificação dos topônimos de origem indígena como hidrotopônimos, inseriu-se nesta taxe apenas aqueles que apresentam a lexia tupi $y$ em seu significado de água ou rio, em posição sintagmática inicial, como em Ipirá, concordando com as considerações de Dick (1990) para essas formações aglutinadas.
} 


\begin{tabular}{|l|l|}
\hline 17 - Semiárido Nordeste II & Ribeira do Pombal \\
\hline 18 - Litoral Norte e Agreste Baiano & $\begin{array}{l}\text { Alagoinhas } \\
\text { Rio Real }\end{array}$ \\
\hline 20 - Vitória da Conquista & Poções \\
\hline 21 - Recôncavo & Cachoeira \\
\hline 22 - Médio Rio de Contas & Ipiaú \\
\hline 23 - Bacia do Rio Corrente & Correntina \\
\hline 24 - Itaparica & Chorrochó \\
\hline
\end{tabular}

Quadro 1 - Relação dos hidrotopônimos conforme os Territórios de Identidade.

Fonte: PRUDENTE, 2017.

Localizado no Polígono da Seca, o TI 01, tem, no hidrotopônimo Irecê "sobre águas, por causa da água ou rio subterrâneo" (IBGE, 1958, v. XX, p. 291), a representação da ausência sentida da água no semiárido baiano e está associado, segundo Miranda (2010), à estratégia de sobrevivência de sua população, na fase inicial de povoamento, de dispersar-se em busca de água nos períodos de muita escassez.

O Rio São Francisco marca, efetivamente, a identidade do TI 02 e é considerado como o principal responsável pela chegada do colonizador à região, fazendo-se presente na formação da cultura e dos hábitos de seus moradores. No corpus estudado, a presença das águas do Velho Chico e seus afluentes se reflete nos hidrotopônimos Barra, onde o Rio Grande, seu maior afluente, faz a sua "barra", isto é, nele desemboca suas águas, e Paratinga (ou Parapitinga, o grande rio branco ${ }^{3}$ ) como o São Francisco era denominado pelo gentio.

A conjunção de fatores naturais proporciona ao TI 03 uma beleza singular e os seus recursos hídricos estão presentes também nos seus hidrotopônimos, como em Barra da Estiva, referente ao encontro do Riacho da Prata com o Riacho da Estiva. Em um processo de translação toponímica, ou seja, o deslocamento do designativo de um acidente para outro ${ }^{4}$, as águas dos rios da Chapada permanecem nos topônimos Rio de Contas, herdado do Rio de Contas Pequeno (atual Rio Brumado), um dos principais

\footnotetext{
${ }^{2}$ Designativo criado pelo tupinólogo Theodoro Sampaio (IBGE, 1958), em reconhecimento ao fato que garantiu o florescimento do povoado, a ação de perfurar o solo para encontrar água.

${ }^{3}$ O Rio São Francisco também recebia o nome de Opará, o rio-mar. A forma pará, na língua brasílica, tem o sentido de rio grande, como um mar (DICK; SEABRA, 2002).

${ }^{4}$ Embora esse processo possa ser circular, isto é, o nome seja deslocado do rio para o povoamento formado em suas margens ou deste para aquele, segundo Dick e Seabra (ibidem), em Toponímia, constitui-se um princípio o fato de que os nomes de cursos d'água, montanhas e serras sejam os mais primitivos ou as mais antigas denominações. Outros exemplos de translação toponímica, em que os nomes dos rios foram adotados pelos aglomerados surgidos as suas margens, foram encontrados no corpus analisado: Aratuípe, Brumado, Carinhanha, Inhambupe, Itapicuru, Jaguaripe, Jiquiriçá, Macarani, Pojuca, Una.
} 
afluentes do Rio de Contas; e Utinga (“água branca”, ), que recebe o nome do Rio Utinga, o rio das águas claras.

Inserido na região da Bacia Hidrográfica do Recôncavo Sul, o TI 06 constitui-se em uma área extremamente rica em recursos hídricos, com cursos d'água e expressivos complexos de mangues e quedas d'água. Considerando que os principais centros urbanos da região foram formados nas proximidades desses cursos d'água, os hidrotôponimos Camamu ("água do seio") e Ituberá ("cachoeira brilhante”) representam mais exemplos de translação toponímica, com as povoações formadas adotando e preservando os primitivos nomes dos seus acidentes hídricos.

Caracterizado pela grande diversidade climática, com áreas semiáridas coexistindo com espaços úmidos a subúmidos, o TI 08 encontra no hidrotopônimo Iguaí ("pequeno lagamar, bacia fluvial") a discreta presença da água em seu território. No TI 10, por outro lado, a aridez do sertão é abençoada pela passagem do Rio São Francisco, que, em seu trecho navegável, diminui o fluxo de suas águas e um grande remanso formava seguro porto de atracação, local escolhido para o surgimento do povoado que deu origem ao município Remanso ${ }^{6}$.

O Rio Paramirim - que batiza o TI 12 - é a principal fonte hídrica e o referente identitário da região, e, em mais um exemplo de translação toponímica, o hidrotopônimo Paramirim ("rio pequeno") ressalta a importância desse rio para a construção da identidade do território. O TI 13, por sua vez, encontra-se dentro da Serra Geral e constitui-se na ligação entre a Chapada Diamantina e a Serra do Espinhaço. O hidrotopônimo Ituaçu ("cachoeira grande") estabelece a relação entre a geomorfologia da região e a presença da água do Rio de Contas e seus afluentes.

Marcado pela aridez do clima e pela escassez de recursos hídricos, o TI 15 é cortado pela bacia do Rio Jacuípe, que, com sua barragem, abastece os municípios do território e tem sua importância registrada no hidrotopônimo Riachão do Jacuípe, município localizado de forma privilegiada à sua margem direita. Já o hidrotopônimo Ipirá ("rio do peixe") tem como causa nominativa o seu correspondente em português, o Rio do Peixe, um rio piscoso que corta a região.

O TI 17 localiza-se na região semiárida do nordeste baiano, com o predomínio do bioma Caatinga e clima quente e seco, marcado por altas temperaturas. Com índices pluviométricos extremamente baixos, solos rasos, arenosos e cascalhentos, incapazes de reter grande volume de água, o hidrotopônimo Ribeira do Pombal representa a esperança na desejada presença da água. Localizada no caminho para o Rio São Francisco, o

\footnotetext{
${ }^{5}$ Para a determinação do sentido dos topônimos de origem indígena, presentes no corpus estudado, tomouse se por base as seguintes obras: Contribuição indígena ao Brasil, do Irmão José Gregório, publicada em 1980; Dicionário de topônimos brasileiros de origem tupi, de Luiz Caldas Tibiriçá, publicado em 1985; Dicionário de Tupi Antigo, de Eduardo de Almeida Navarro publicado em 2013; O tupi na geografia nacional, de Theodoro Sampaio, edição de 2014.

${ }^{6}$ Pelo Decreto Federal n. 10/77, de 28-01-1977, a sede municipal do município Remanso foi transferida para local distante $7 \mathrm{~km}$ da cidade velha, inundada pelas águas da Barragem Sobradinho, no Rio São Francisco.
} 
município ficou muito conhecido, na época do povoamento da região, como pouso dos viajantes que se dirigiam para aquele rio.

Além de áreas alagadas, como brejos, lagoas, manguezais e cascatinhas, o TI 18 é marcado pela presença de importantes bacias, como as dos rios Real, Itapicuru, Itariri, Inhambupe, Subaúma, Sauípe, Imbassaí e Pojuca. Essa presença abençoada, responsável pela fertilidade do território, evidencia-se no hidrotopônimo Alagoinhas, uma referência às inúmeras lagoas da região, e na translação dos nomes dos rios, fundamentais no período inicial do processo de colonização, para os municípios: Inhambupe, Itapicuru, Pojuca e Rio Real.

A existência de água como fator fundamental para o surgimento das povoações do TI 20 se evidencia no hidrotopônimo Poções, que se refere aos grandes poços encontrados pelos colonizadores em suas explorações à procura de minas auríferas. Já no TI 21, a presença da água é assegurada pelas bacias dos rios Rio Paraguaçu, Subaé e Jaguaripe. Situado próximo às quedas d'água presentes na cabeceira do Rio Paraguaçu, o município de Cachoeira reflete em seu hidrotopônimo a importância desse rio que, por muito tempo, foi a principal via de transporte e comunicação da região e guarda a lembrança do tempo em que, em suas águas, o simbólico "Vapor de Cachoeira" fazia a ligação entre Salvador e todo o Recôncavo.

Localizado na zona de transição entre os biomas Mata Atlântica e Caatinga, o TI 22 apresenta paisagens contrastantes e ampla diversidade climática. Entre suas bacias hidrográficas, destaca-se a do Rio de Contas, um dos maiores do Estado em extensão de curso. De importância fundamental para a subsistência da região, o Rio de Contas é fruto da contribuição de dezenas de riachos, córregos, ribeirões e rios perenes ou temporários, como o Rio Água Branca, originalmente conhecido como Rio Novo, em cujas margens se formou o povoado que deu origem ao município Ipiaú ("rio novo").

Situado na região oeste da Bahia, em uma das extremidades do Estado, o TI 23 encontra no Rio Corrente, afluente do Rio São Francisco, não apenas a causa nominativa, mas sua base de vida e marca de identidade. Faz parte da memória da população a época em que todo o comércio local era feito pelo rio, e o hidrotopônimo Correntina reconhece, no Rio Correntina (antigo Rio das Éguas), um dos afluentes formadores do Rio Corrente, a importância dos rios para o surgimento e desenvolvimento da região.

Com uma identidade cultural marcada pela junção de culturas e a principal atividade econômica relacionada ao fornecimento de energia elétrica para a Bahia e demais estados nordestinos, o TI 24 também apresenta uma forte relação identitária com o Rio São Francisco. Tal relação evidencia-se no hidrotopônimo Chorrochó ("muito correntoso, muito impetuoso") como o gentio considerava esse rio em um dos seus trechos menos navegáveis. 


\section{CONSIDERAÇÕES FINAIS}

Compreendendo a língua como manifestação da cultura de um povo e reconhecendo os signos toponímicos como elementos de identificação cultural, a análise aqui desenvolvida buscou relacionar a presença (ou ausência) dos recursos hídricos da Bahia ao espaço nomeado e comprovar a importância da pesquisa toponímica para a reconstituição do passado e compreensão do presente, contribuindo, assim, para a preservação da memória cultural do Estado.

O número significativo de hidrotopônimos encontrado no corpus analisado e suas relações culturais e identitárias com os territórios onde estão inseridos demonstram o quanto a água, elemento fundamental para a existência da vida, impressionou os primeiros nomeadores do espaço e se constituiu em fator preponderante para a sobrevivência e fixação do homem na terra nos caminhos da Bahia.

\section{REFERÊNCIAS}

BAHIA. Bahia em números. v. 3. Edição bilíngue: português e inglês. Superintendência de Estudos Econômicos e Sociais da Bahia-SEI. Salvador: SEI, 2001. Disponível em: <http://www.sei.ba.gov.br>. Acesso em: 20 abr. 2016.

BAHIA. Plano Estadual de Recursos Hídricos. Superintendência de Recursos Hídricos da Bahia-SRH. Salvador: SRH, 2003. Disponível em:

<licitacao2.codevasf.gov.br/licitacoes/sede-brasilia...ba/relatorio_final-1.pdf>. Acesso em 20 jul. 2017.

BAHIA. Decreto n. 12354 de 25 de agosto de 2010. Institui o Programa de Territórios de Identidade e dá outras providências. Diário Oficial do Estado, 26 de agosto, 2010. Disponível em: <http://dovirtual.ba.gov.br/egba/reader2/>. Acesso em 20 abr. 2016.

CEDETER. Territórios de Identidade da Babia (mapa). Conselho Estadual de Desenvolvimento Territorial (CEDETER), Salvador. 2011. Disponível em: $<$ https://territoriosculturaisbahia.wordpress.com/divisao-territorial/>. Acesso em 23 jul. 2017.

DICK, M $\mathrm{M}^{\mathrm{a}}$ Vicentina de Paula do Amaral. A motivação toponímica e a realidade brasileira. São Paulo: Edições do Arquivo do Estado, 1990.

DICK, M ${ }^{a}$ Vicentina de Paula do Amaral. Coletânea de Estudos. 3. ed. São Paulo: FFLCH/USP, 1992.

DICK, M ${ }^{a}$ Vicentina de Paula do Amaral; SEABRA, Ma Cândida Trindade Costa de. Caminho das águas, povos dos rios: uma visão etnolinguística da toponímia brasileira. 
Cadernos do CNLF, Rio de Janeiro, v. 5, p. 25-32, 2002. Disponível em: < http://www.filologia.org.br/vcnlf/anais\%20v/civ6_07.htm>. Acesso em 20 abr. 2016.

DICK, Ma Vicentina de Paula do Amaral. Atlas Toponímico do Brasil: Teoria e Prática II. In: Revista Trama, v. 3, n. 5. Universidade Estadual do Oeste do Paraná, 2007. p. 141 155

GREGÓRIO, Irmão José. Contribuição indígena ao Brasil. Belo Horizonte: União Brasileira de Educação e Ensino, 1980.

IBGE. Enciclopédia dos Municípios Brasileiros. v. XX/XXI. Rio de Janeiro: Serviço Gráfico do IBGE, 1958.

ISQUERDO, Aparecida Negri. O nome do município. Um estudo etnolinguístico e sóciohistórico na toponímia sul-mato-grossense. In: Revista Prolíngua, v. 2, n. 2, jul/dez, 2008. p. 34-52.

MIRANDA, Dayse Lago de. Universidade do Estado da Babia/UNEB e o desenvolvimento territorial sustentável: estudo da relação do campus XVI com o Território de Identidade de Irecê. 2010. Dissertação (Mestrado). PPGEduC, UNEB. Salvador, 2010. Disponível em: $<$ http://www.cdi.uneb.br/pdfs/educacao/2010/dayse_lago_de_miranda.pdf $>$. Acesso em 20 mar. 2016.

NAVARRO, Eduardo de Almeida. Dicionário de Tupi Antigo. A língua indígena clássica do Brasil. São Paulo: Global, 2013.

PRUDENTE, Clese Mary. Babia de todos os cantos e recantos: marcas identitárias e culturais na toponímia da Bahia. 2017. Dissertação (Mestrado). Departamento de Ciências Humanas. Programa de Pós-Graduação em Estudo de Linguagens, Universidade do Estado da Bahia, Salvador, 2017.

SAMPAIO, Theodoro. O tupi na geografia nacional. 2. ed. São Paulo: O Pensamento, 1914. TIBIRIÇÁ, Luiz Caldas. Dicionário de topônimos brasileiros de origem tupi. São Paulo: Traço Editora, 1985.

Recebido em: 02/05/2017 